Please do not remove this page

RMIT

UNIVERSITY

\title{
The development and testing of a hierarchical measure of project OHS performance
}

Lingard, Helen; Wakefield, Ronald; Cashin, Patrick

https://researchrepository.rmit.edu.au/esploro/outputs/9921858106401341/filesAndLinks?institution=61RMIT_INST\&index=null

Lingard, H., Wakefield, R., \& Cashin, P. (2011). The development and testing of a hierarchical measure of project OHS performance. Engineering, Construction and Architectural Management, 18(1), 30-49. https://doi.org/10.1108/09699981111098676

Document Version: Accepted Manuscript

Published Version: https://doi.org/10.1108/09699981111098676

Repository homepage: https://researchrepository.rmit.edu.au

(c) Emerald Group Publishing Limited

Downloaded On 2023/04/26 11:51:08 +1000

Please do not remove this page 
Thank you for downloading this document from the RMIT Research Repository.

The RMIT Research Repository is an open access database showcasing the research outputs of RMIT University researchers.

RMIT Research Repository: http://researchbank.rmit.edu.au/

\section{Citation:}

Lingard, $\mathrm{H}$ and Wakefield, $\mathrm{R} 2011$, 'The development and testing of a hierarchical measure of project OHS performance', Engineering, Construction and Architectural Management, vol. 18 , no. 1 , pp. 30-49.

See this record in the RMIT Research Repository at:

https://researchbank.rmit.edu.au/view/rmit:12373

Version: Accepted Manuscript

Copyright Statement: (c) Emerald Group Publishing Limited

Link to Published Version:

http://dx.doi.org/10.1108/09699981111098676 


\title{
The development and testing of a hierarchical measure of project OHS performance
}

\author{
Helen Lingard ${ }^{1}$, Ron Wakefield ${ }^{2}$, Pat Cashin $^{3}$
}

\begin{abstract}
A hierarchical measurement model for OHS performance was developed for use in the Australian construction industry. This model involved the measurement of OHS performance using a combination of lagging (outcome) and leading (process) indicators and a safety climate survey. Two measurement tools were developed and tested on one case study construction project in Australia. The tools, a monthly weighted safety index and a quarterly safety climate survey were used to measure OHS performance and performance data are presented. The data suggest convergent validity, indicated by consistent results between the two measures. Results also indicated that a combination of measurement techniques provides more comprehensive data pertaining to project OHS performance and enables the diagnosis of OHS issues that would be undetected with reliance exclusively on traditional measures, such as lost time injury frequency rates. The implications for practice are that multiple measures of OHS performance, including leading indicators and surveys of workers' attitudes and perceptions of project OHS, provide a more useful basis for the development of targeted OHS improvement strategies. The implications for future research lie in the demonstrated need to carefully evaluate the validity of the safety index and safety climate survey in future construction projects, and in the broader construction context.
\end{abstract}

Keywords: occupational health and safety, performance, measurement, key performance indicators, climate survey

\section{Introduction}

Why measure OHS performance?

The measurement of performance is a critical component of any occupational health and safety (OHS) management system. For example, AS/NZS 4801: Occupational health and safety management systems - General guidelines on principles, systems and supporting techniques, states that 'An organization should measure, monitor and evaluate its OHS performance, and take preventive and corrective action.' (Standards Australia, 2001, p35). Measuring OHS performance helps to ensure that organizations are achieving their OHS policy objectives and targets. OHS performance measurement provides information regarding how organizations (or organizational sub-units) are performing with regard to OHS and allows organizations to identify problem areas in which improvements can be made. This early detection of OHS problems enables timely corrective or improvement action to be taken. Performance measurement is also required if the effects of organizational OHS interventions are to be properly evaluated as it provides important feedback about what works and what doesn't. Performance measurement provides the basis for reviews of OHS practices and organizational processes and can also be used for comparative analysis and/or benchmarking, either between sub-units within one organization or between organizations within the same industry (NOHSC, 1999).

\section{The need for OHS measurement in the construction industry}

OHS in the construction industry is a persistent problem. In Australia between 1994 and 2000, 50 construction workers were killed each year as a result of their work. The average fatality rate, at 10.4 per 100,000 persons is similar to the national road toll fatality rate (McWilliams et al 2001) and the rate of serious injury is 50\% higher than the all industry average (Cole 2003). In order to bring about sustained improvements in OHS performance in the construction sector, rigorous, reliable and valid measurement of OHS performance is required.

\footnotetext{
${ }^{1}$ School of Property, Construction and Project Management

${ }^{2}$ School of Property, Construction and Project Management

${ }^{3}$ Baulderstone Hornibrook Pty Ltd.
} 
In order to be of use, OHS performance measures must be valid. A valid indicator is one that is a true measure of the concept in which we are interested, in this case OHS performance (Neuman, 1994). Validity is sometimes difficult to gauge, especially in the measurement of abstract concepts like attitudes towards OHS. This is because abstract ideas sometimes do not correspond to the observable indicators we use to measure them. However, validity is an important consideration in any measurement and, particularly when developing new measures, validity needs to be carefully assessed.

\section{Aims of the paper}

This paper reports on innovative occupational health and safety (OHS) measures implemented in one large civil engineering construction project in the Australian construction industry.

Specific objectives of the paper are:

1. to identify different types of OHS performance measurement;

2. to develop a hierarchical model for the measurement of OHS performance;

3. to describe the application of this model in the measurement of OHS performance within the case study construction project;

4. to present OHS performance data collected from the case study construction project; and

5. to explore validity of the OHS measures described.

\section{Types of OHS measures}

AS/NZS 4801 recommends that measurable indicators be established, to measure OHS performance against objectives. The New South Wales Health Department (1998) defines a performance indicator as 'a statistic or other unit of information which reflects directly or indirectly, the extent to which an anticipated outcome is achieved, or the quality of processes leading to that outcome' (NOHSC, 1999, p1). Many performance indicators are quantitative, for example the number of injuries occurring within a given time or the number of OHS inspections conducted. However, performance indicators can also be qualitative, for example workers' subjective judgements about management commitment to OHS.

\section{Traditional (lagging) measures}

Success in OHS has traditionally been measured by the absence of outcomes, such accidents, injuries, illnesses or diseases (Arezes \& Miguel 2003). OHS measures based upon outcomes are sometimes referred to as 'lagging' indicators because they measure events that have already happened. Outcome measures, such as Lost Time Injury Frequency Rates (LTIFR) can usually be compared between companies and industries because they are based upon standard formulae. For example, AS 1885.1-1990: Workplace injury and disease recording standard specifies ways in which OHS statistics should be calculated. The LTIFR is the number of injuries $x$ 1,000,000 divided by the total man hours worked. Outcome measures have become standard measures of OHS performance in the Australian construction industry. They are useful in that they are:

- relatively easy to collect;

- easily understood;

- arguably the most valid indicators of OHS performance;

- easy to use in benchmarking or comparative analyses; and

- useful in the identification of trends (NOSHC, 1999).

However, lagging indicators of OHS performance measures are also limited in a number of important ways. First, because reportable injuries and illnesses have a statistically low probability of occurring, measurement based solely upon such events is not sensitive enough to identify changes to OHS performance, especially at a project level. Outcome measures record failures 'after the fact.' As such, they do not permit the timely implementation of 
preventive or corrective OHS measures. Outcome indicators are subject to random variation, meaning that even a stable safety system will produce a variable number of injury events (Stricoff, 2003). Managers' responses to fluctuations in the LTIFR can create a so-called 'accident cycle.' In this cycle, when the LTIFR increases, management expend considerable effort in OHS to reduce this rate. However, once the rate has fallen back to its original level, attention to OHS declines and the LTIFR rises once again. This cycle of 'knee jerk' reactions to fluctuations in the LTIFR is counter-productive to continuous improvement in OHS (Stricoff, 2003). Further, a low LTIFR does not guarantee that OHS risks are being controlled or that work-related injuries or diseases will not occur in the future. Thus, while the LTIFR is a valid (or true) indicator of past OHS performance, its reliability as a predictor of future OHS performance is questionable. This is especially true where there is a low probability of accidents but where major hazards are present in the work environment (HSE, 2001).

The way that lagging performance measures have been used also presents some problems for the effective reduction of occupational injury and illness. Injury frequency rates, for example, are sometimes related to reward systems, managers' performance appraisals, bonus payments or future tendering opportunities. When used in this way, under-reporting is encouraged. Indeed, the greater the emphasis that is placed upon outcome or lagging OHS indicators, the less valid(and useful) these measures may be because people learn how to manipulate the figures. Under-reporting of injuries is a recognised problem. Indeed, Daniels and Marlow (2005) suggest that the level of reporting of non-fatal construction injuries in the UK construction industry is as low as $46 \%$. Another practice widely believed to impact upon LTIFRs involves managing workers' injuries to reduce their financial impact upon the organization. For example, injured workers are sometimes returned to work on 'light' duties' to avoid reporting a lost time injury (Hopkins, 1995).

A further problem with most commonly used lagging OHS measures is that they do not accurately measure occupational illnesses with a long latency period, such as occupational cancers or chronic problems like musculoskeletal disorders. Neither do lagging measures assist in identifying the causes of incidents, reducing their usefulness in the diagnosis of OHS problems.

\section{Leading (positive) performance indicators}

As a result of these limitations, there has been a move away from the exclusive use of retrospective data for the measurement of OHS performance in favour of the use of leading indicators (WorkSafe Australia 1994; NSW WorkCover Authority 2001; DEWR/ASCC, 2005). Leading indicators (sometimes called process measures or positive performance indicators) of OHS, try to capture how well an organization (or organizational sub-unit) is managing OHS, for example, by quantifying how many workers have received OHS training, how many OHS inspections have been conducted etc. Thus, leading indicators measure positive steps to manage OHS before the occurrence of incidents or injuries.

There are a number of important advantages in the use of leading OHS indicators. First, leading indicators provide a more direct measure of the quality of OHS management and an immediate feedback mechanism, enabling organizations to improve OHS management processes, before deficiencies have resulted in incidents, injuries or illnesses.

Despite these significant advantages, one potentially serious weakness associated with the use of leading indicators of OHS performance is that the relationship between specific leading indicators developed and outcome measures of OHS (injuries and illness) is often not known. For example, managers may not know to what extent the numbers of workers who have received OHS training or the number of management safety walks that have taken place 
predicts the occurrence of injuries or illnesses in the future. Consequently, the validity of leading indicators of OHS performance is sometimes questioned. For this reason, leading indicators are recommended for use in addition to (rather than in the place of) traditional outcome measures of OHS performance (DEWR/ASCC, 2005).

\section{Measurement of OHS attitudes \& perceptions}

A third, type of measurement of organizational OHS performance involves assessing the workers' attitudes and perceptions of the work environment. Such attitudes and perceptions are most frequently measured using a safety climate survey. Safety climate is said to represent the 'surface features of the safety culture discerned from the workforce's attitudes and perceptions at a given point in time' (Flin et al 2000, p178) and the measurement of safety climate is widely recommended as a measure of the underlying safety culture of an organization or workplace (Mearns et al 2003; French, 2004). Since the safety climate concept was first advanced in a seminal paper by Zohar (1980), many different safety climate measurements tools have been developed. Unfortunately, measurement of the safety climate concept has been characterised by a lack of consistency in the number of climate components and a failure to replicate different climate models across organizations and industries. This has led some theorists to suggest that no single, uniform set of safety climate dimensions exists (Coyle et al 1995). However, Flin et al (2000) note that some common components of safety climate can be observed in the published literature. These include: management commitment to OHS; supervisory OHS behaviour; the relative priority of OHS over production and time pressure; and the quality of safety-related communication within the organization (Flin et al 2000). There is also emerging evidence to support the predictive and/or criterion validity of safety climate measures. For example, a number of researchers report statistically significant relationships between safety climate scores and the incidence of occupational accidents (Varonen \& Mattila 2000; Mearns et al 2003).

Safety climate measures can provide in-depth information about the root causes of OHS problems and are a useful diagnostic tool. They also provide a deeper level of analysis than outcome or even process measures of OHS. For example, it is possible to attain a high score in the number of workers receiving OHS training or the number of worksite inspections undertaken but still for there to exist an organizational culture that de-emphasizes OHS relative to other organizational or project goals, such as production or cost performance. Safety climate has been reliably measured in the construction industry (Glendon \& Litherland, 2001; Siu et al 2004). However, a review of safety performance measures in the Australian construction industry identified safety climate surveys as indicators that participating organizations do not use at present but would like to use in the measurement of OHS (NOHSC, 1999).

\section{Need for multiple measures}

The literature suggests that there is no single reliable measure of organizational OHS performance. It is now widely accepted that outcome or lagging indicators should be supplemented with alternative OHS measurement methods, including leading performance indicators and safety climate assessments. Ideally, a combination of measures should be used to overcome the limitations inherent in one type of measure, as well as providing the opportunity for 'triangulation', i.e. checking the consistency of OHS performance data generated from different measures of performance (Patton, 1990).

Some researchers recommend that OHS performance should be measured using a hierarchical set of linked measures (Arezes \& Miguel, 2003; Tinmannsvik \& Hovden 2003). Such a hierarchical method is proposed in Figure 1. This model represents the OHS performance measurement framework developed within one large Australian construction contracting 
organization. The framework comprises three levels of measurement including lagging indicators (Level 1), leading indicators (Level 2) and measurement of OHS attitudes and perceptions (Level 3). These measures are positioned on a continuum, ranging from Level 1 measures, which are observable, objective, quantifiable and reactive to Level 3 measures which are difficult to observe, subjective in nature, based on qualitative descriptors and proactive. Ultimately the validity of Level 2 (leading indicators) and Level 3 (OHS attitudes and perception scores) must be ascertained by the extent to which these measures are significantly correlated with objective outcome indicators of OHS performance, such as injury/incident rates. In this paper, we present preliminary data collected using this three-tiered model in one large civil engineering construction project. We suggest that, together, these measures present a more useful and valid basis for measuring organizational or project OHS performance than the use of any of a single type of OHS indicator.

\section{Figure 1: Hierarchical OHS measurement model}

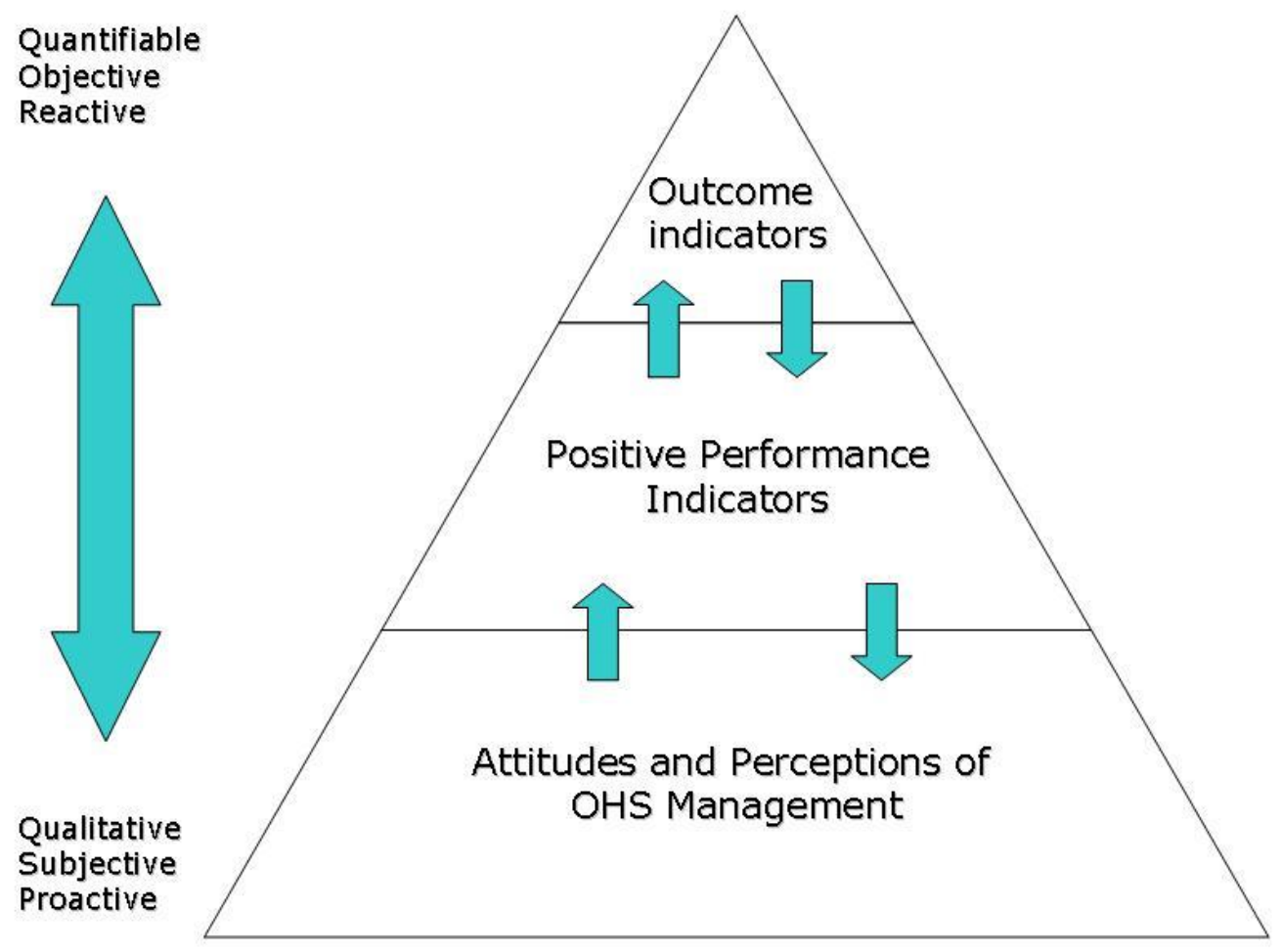

\section{The case study project}

The measurement was developed and tested on the Tullamarine Calder Interchange project, a $\$ 150$ million Australian dollar upgrade of the interchange between the Tullamarine and Calder Freeways in Melbourne, Victoria. The project was commenced in October 2005 and is due for completion in late 2007. The project is being delivered through an alliance arrangement between Baulderstone Hornibrook, Parsons Brinckerhoff and VicRoads. The project involves work adjacent to operational airport at an interchange used by an estimated 176,000 vehicles a day, presenting a significant level of OHS risk to workers and road users. Construction work is organized to minimise the impact on peak travel periods and ensure that 
24 hour access to Melbourne and Essendon airports is maintained. It is estimated that the total number of manhours for the project will be 460,000, upon completion.

\section{The OHS measurement tools}

\section{Project safety index}

The project safety index combines a number of lagging and leading OHS performance indicators. Each of these indicators is given a weighting as to its level of importance in determining the overall OHS performance score. Performance against these indicators is assessed on a monthly basis to obtain a rating of overall project OHS performance. The safety index has a number of strengths:

- it can be easily applied to multiple projects and data from each project can be easily compared;

- areas of weakness in the OHS management system can be quickly identified; and

- any necessary corrective action can be put in place.

As it includes leading as well as lagging OHS performance indicators, the index provides a balanced measurement of the quality of OHS management in a project, enables the early detection of deficiencies and permits the rectification of OHS problems, before injuries or illnesses occur. Table 1 shows the safety index components and weightings.

\section{Table 1: Safety Index components and weightings}

\begin{tabular}{|c|c|c|}
\hline Indicator & Weighting & Leading/lagging \\
\hline 1. Members of the public injured & 0.35 & Lagging \\
\hline 2. Medically treatable injuries & 0.05 & Lagging \\
\hline 3. First aid incidents & 0.05 & Lagging \\
\hline 4. Lost time injury & 0.3 & Lagging \\
\hline $\begin{array}{l}\text { 5. Incident/Near miss incidents } \\
\text { reported }\end{array}$ & 0.05 & Leading \\
\hline 6. Safety walks & 0.05 & Leading \\
\hline $\begin{array}{l}\text { 7. Safety walk observations } \\
\text { (problems noted) }\end{array}$ & 0.05 & Lagging \\
\hline $\begin{array}{l}\text { 8. Site safety inspections } \\
\text { conducted }\end{array}$ & 0.025 & Leading \\
\hline $\begin{array}{l}\text { 9. Site safety inspection problems } \\
\text { noted }\end{array}$ & 0.025 & Lagging \\
\hline 10. Safety assessments & 0.025 & Leading \\
\hline $\begin{array}{l}\text { 11. Safety assessment problems } \\
\text { identified }\end{array}$ & 0.025 & Lagging \\
\hline
\end{tabular}

The index comprises approximately $40 \%$ leading and 60\% lagging indicators as indicated in Table 1. The index provides a measure of performance against industry benchmarks in relation to the lagging indicators. Benchmarks were established from statistics on Medical Treated Injuries (MTI) and Lost Time Injuries (LTI) compiled by the leading Australian construction companies over the last ten years. The indicators and weightings that make up the index were developed collaboratively by the project team to encourage particular types of behaviour and to provide disincentives, particularly in relation to lagging indicators. For example the weightings placed on Medical Treated Injuries (MTI), Lost Time Injuries (LTI) and Members of the Public Injured are such that, if any of these incidents occur in a measurement period, the index score cannot exceed 60\%. Data were collected using the project safety index on a monthly basis. Data from October 2005 to July 2006 are presented in this paper. 


\section{Project climate survey}

An OHS climate survey tool was developed to measure four dimensions of safety climate at a project level. Original safety climate dimensions included in the instrument were:

management commitment to OHS; OHS communication; supervisory leadership in OHS and co-worker support for OHS. The first two dimensions are common components of safety climate measures in the literature (Flin et al 2000), reflecting the fact that managers' OHS behaviours and communication in OHS matters are consistently linked to OHS performance in an industrial context (Shannon et al 2001; Vredenburgh 2002; Varonen and Mattila 2000). However, research also indicates that first level supervisors have a stronger, more direct influence on subordinates' OHS behaviour than managers (See Simard and Marchand 1994; 1995; 1997), suggesting that perceptions of supervisory behaviour would be a useful climate dimension. Supervisory issues, such as supervisor supportiveness (Parker et al 2001), the quality of supervisor-subordinate relationships (Hofman and Morgeson 1999) and supervisors' transformational leadership qualities (Barling et al 2000) have all been linked to good OHS performance within work groups. Further research reveals that social processes within work groups also play an important role in determining the OHS behaviour and performance of group members. (Zohar 2000; Zohar 2002; Hofmann and Stetzer 1996). Thus, perceptions of co-workers' support for OHS (labelled 'co-workers' safety stewardship') were also measured in the project safety climate survey.

A minimum of three items were developed for each of the four safety climate dimensions. Example items are:

- As long as work remains on schedule, managers do not care how this has been achieved (reverse scored) [management commitment to OHS];

- I feel comfortable raising my OHS concerns with a project (management) representative [OHS communication];

- My supervisor recognises and supports safe behaviour [supervisory safety leadership]; and

- My co-workers look out for my health and safety [co-workers' safety stewardship].

Respondents were asked to rate the extent to which each of these items applied in their current project on a seven point Likert scale from 1 (Strongly disagree) to 7 (Strongly agree).

Following an initial piloting and testing period, the project safety climate survey was administered on a quarterly basis. Thus, the first administration of the survey occurred in January 2006. The survey was re-run in June 2006, providing the two quarterly datasets reported on in this paper. On both occasions workers were invited to a project social function (a barbeque) and invited to complete the survey. Surveys were completed anonymously and collected in a sealed 'ballot box' so surveys could not be linked to individual respondents.

\section{Results}

\section{Safety index scores}

Figure 2 shows the overall weighted safety index scores for the project from October 2005 to July 2006. These results suggest a consistently high level of OHS performance, as measured by the index, with performance not falling below $96.5 \%$ in the time period. This consistently high performance is reflected in the fact that, during the period of measurement, the project experienced zero lost time injuries. ${ }^{4}$ Further, no members of the public were injured as a result of the project during the period of measurement. Given the high weightings placed upon injuries to members of the public (0.35) and lost time injuries (0.30) in the index calculation (See Table 1), the absence of any such occurrences explains the project's consistently high

\footnotetext{
${ }^{4}$ A lost time injury is defined as an occurrence resulting in a fatality, permanent disability or time lost from work of one day/shift or more.
} 
safety index scores. However, the trend line shown in Figure 2 indicates that the linear trend in safety index scores reflects a gradual decline over the time period.

Figure 2: Safety index scores, October 2005-July 2006-08-31

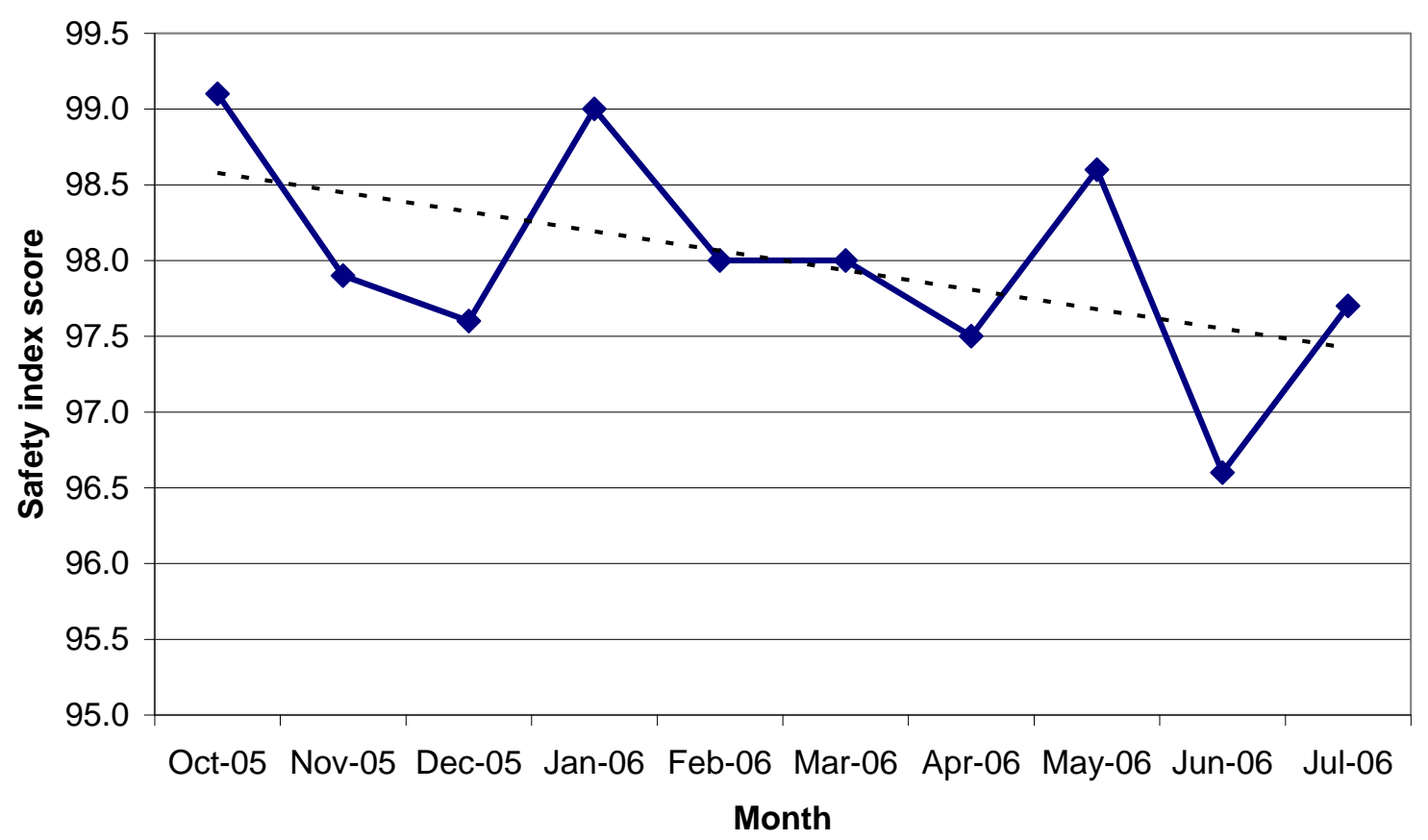

Series1 - - - Linear (Series1)

Closer examination of the safety index component scores reveals changes in performance as measured by some leading indicators of OHS performance. For example, Figure 3 shows reported near miss incidents on the project between October 2005 and July 2006. Reported near miss incidents rose from one (recorded in May 2006) to five (recorded in both June and July 2006). Although absolute numbers of near miss incidents are low, the relatively dramatic increase in June and July over the previous time period indicates that OHS performance deteriorated during this time. Further evidence for this is indicated in Figure 4, which shows a steady increase in the number of safety problems observed during regular 'safety walks' onsite. While the number of observed problems increased gradually throughout 2006, it rose sharply from 15 (recorded in June 2006) to 20 (recorded in July 2006).

Figure 3: Recorded near miss incidents, October 2005-July 2006 (Leading) 


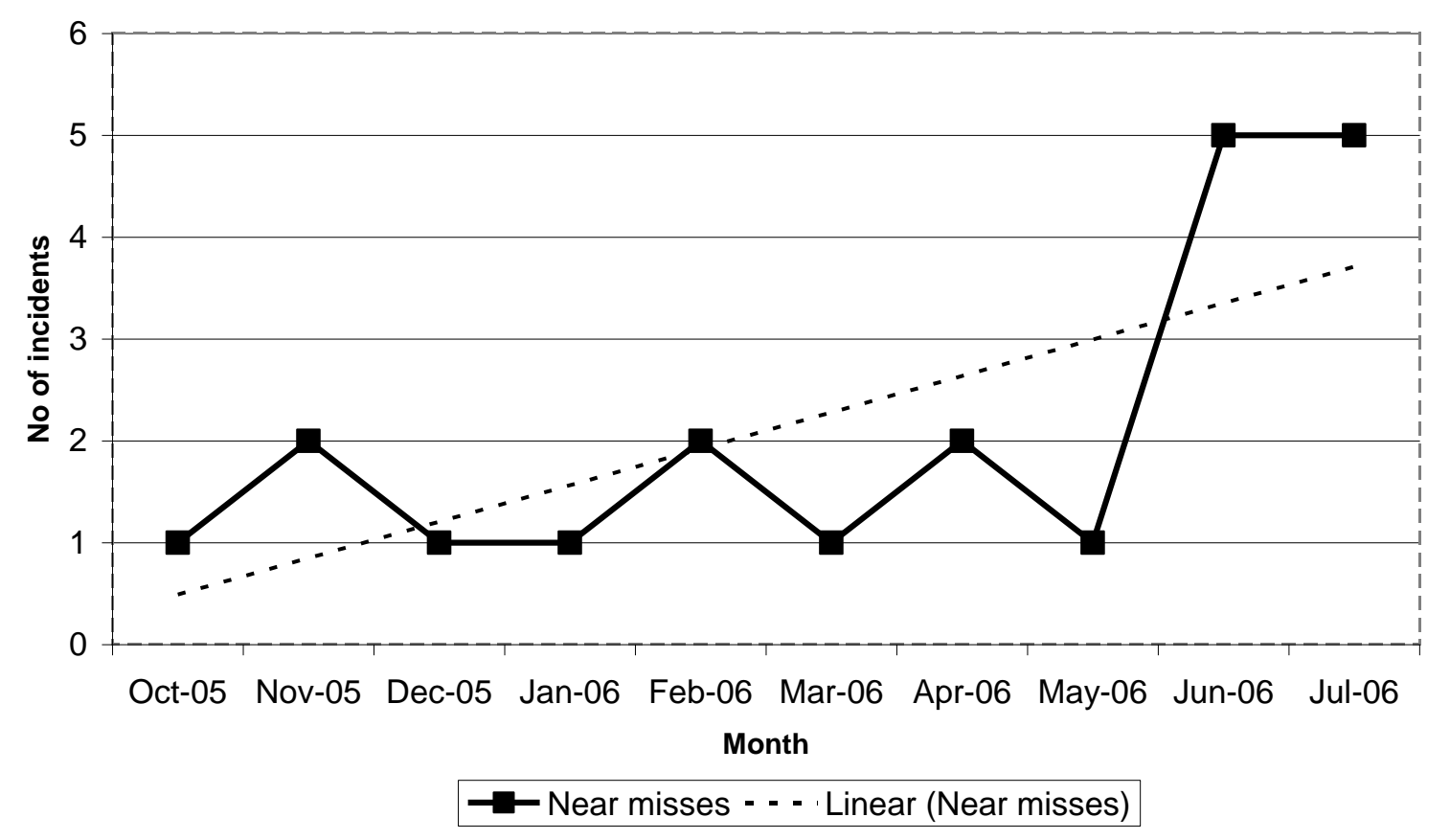

Figure 4: Problems detected during site safety walks, October 2005-July 2006 (Lagging)

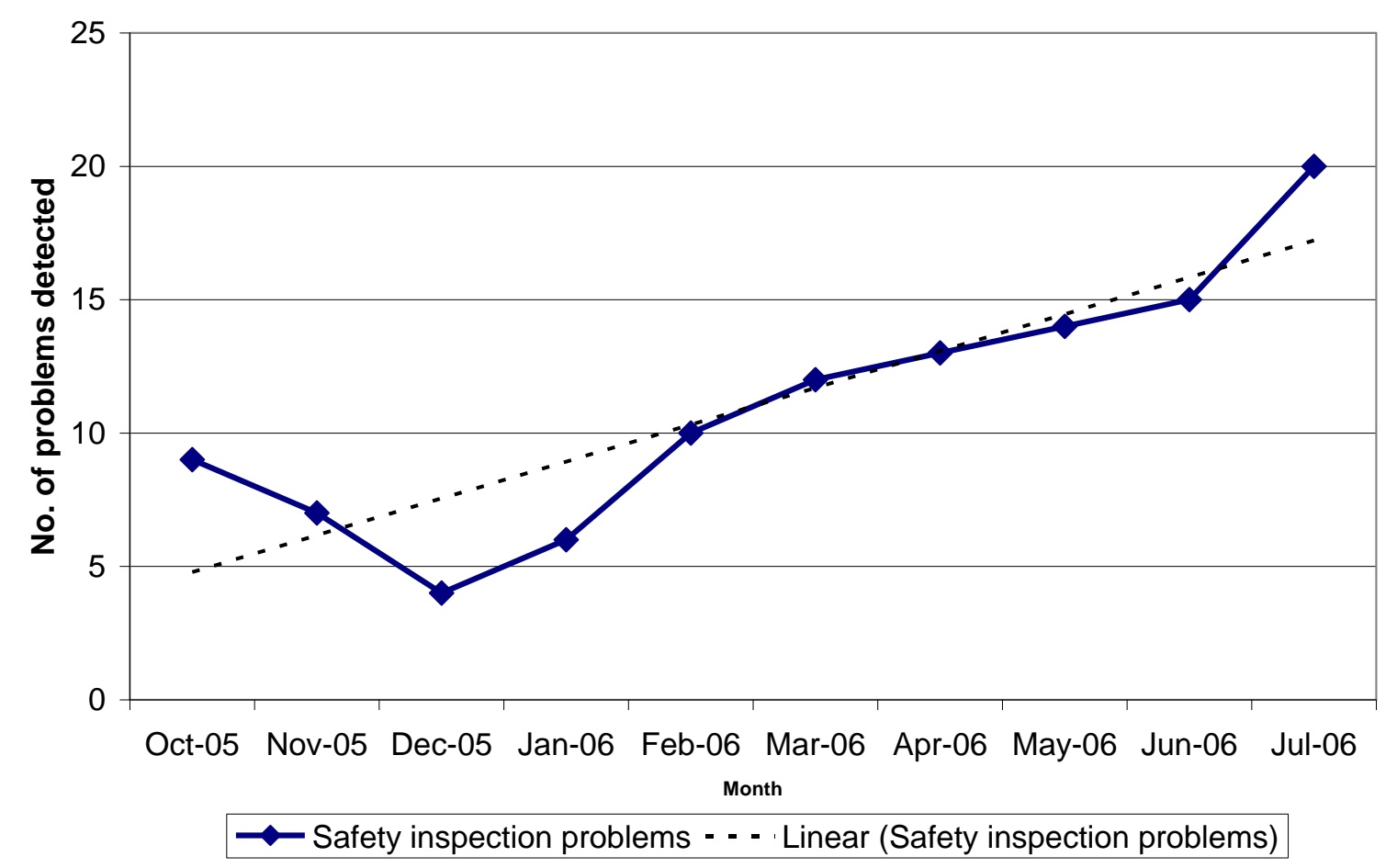

Safety climate measurement

Eighty three completed safety climate surveys were received in the first quarter of 2006. Of these, $48(57.8 \%)$ were completed by workers directly employed by the project and 33 $(39.8 \%)$ were completed by subcontracted workers. Two people $(2.4 \%)$ did not provide employment status. Eighty two completed safety climate surveys were received in the second quarter of 2006. Of these, $61(73.5 \%)$ were completed by workers directly employed by the project and $21(25.3 \%)$ were completed by subcontracted workers. One hundred and thirty eight completed safety climate surveys were received in the third quarter of 2006. Of these, 68 
(49.3\%) were completed by workers directly employed by the project and $70(50.7 \%)$ were completed by subcontracted workers.

Petersen (1998) suggests that safety climate survey questions should elicit a statistically significant response that can be assigned to the various dimensions of the OHS management relevant to OHS performance. Each question should be assigned to a specific dimension in order to identify response patterns. To achieve this, data collected during both quarters $(n=165)$ were subjected to a principal components analysis (PCA), using varimax rotation. An initial unconstrained PCA produced three factors with eigenvalues greater than 1.0. However, inspection of the item loadings indicated that this solution was complex. Given, the theoretical basis of measuring four facets of safety climate (i.e. management commitment to OHS; OHS communication; supervisory leadership in OHS and co-workers' safety stewardship), a forced four-factor solution was generated. The fourth factor was retained since its eigenvalue was .95 (very close to the accepted cut off for retention of 1.0). The four factor model explained $69 \%$ of total variance. In order to assess the internal consistency of the safety climate sub-scales, Cronbach's alpha was calculated for the items loading on each factor. The alpha coefficients ranged from 0.60 to 0.77 (See Table 2).

The rotated components matrix is presented in Table 2 . The matrix shows that the majority of items loaded on the expected factors. However, one item ('The management team genuinely values OHS') unexpectedly loaded with items relating to co-workers' safety stewardship. Reasons for this are unclear but this factor demonstrated an acceptable level of internal consistency (Cronbach's alpha $=0.76$ ) and so the item was retained. Another item 'Workers suggestions for safety improvements are welcomed' double-loaded on co-workers' safety stewardship and OHS communication. As a result, this item was removed from the analysis. The fourth factor included items designed to tap management commitment to OHS. However, as these items failed to load with the third item designed to tap this dimension of safety climate (i.e. 'The management team genuinely values OHS'), the items loading on the fourth factor were examined. In the interests of face validity (See also discussion), the fourth factor was re-named 'OHS as a management priority' to reflect the fact that the two items loading on this factor refer to management's concern for OHS, relative to other project objectives.

Table 2: Safety climate survey items: rotated component matrix

\begin{tabular}{|c|c|c|c|c|}
\hline \multirow[t]{2}{*}{ Item } & \multicolumn{4}{|c|}{ Component } \\
\hline & 1 & 2 & 3 & 4 \\
\hline My supervisor recognises and supports safe behaviour & .906 & & & \\
\hline My supervisor takes safety seriously & .886 & & & \\
\hline My supervisor openly accepts ideas for OHS improvement & .879 & & & \\
\hline My co-workers get involved in OHS activities & & .759 & & \\
\hline My co-workers try to make the site more safe & & .757 & & \\
\hline My co-workers look out for my health and safety & & .649 & & \\
\hline The management team genuinely values $\mathrm{OHS}$ & & .643 & & \\
\hline I have received satisfactory $\mathrm{OHS}$ training & & & .805 & \\
\hline $\begin{array}{l}\text { I have received adequate instructions about } \mathrm{OHS} \\
\text { policies/procedures }\end{array}$ & & & 699 & \\
\hline $\begin{array}{l}\text { I feel comfortable raising my OHS concerns with a project } \\
\text { (management) representative }\end{array}$ & & & .652 & \\
\hline OHS concerns can be openly discussed & & & .561 & \\
\hline $\begin{array}{l}\text { Workers' suggestions for safety improvements are } \\
\text { welcomed }\end{array}$ & & .467 & 499 & \\
\hline $\begin{array}{l}\text { As long as work remains on schedule, managers do not } \\
\text { care how this has been achieved (reverse scored) }\end{array}$ & & & & .760 \\
\hline As long as there are no accidents, managers do not care & & & & 618 \\
\hline
\end{tabular}




\begin{tabular}{|l|c|c|c|c|}
\hline how the work is done (reverse scored) & & & & \\
\hline Eigenvalues & 5.5 & 2.1 & 1.1 & .95 \\
\hline \% variance explained & 39.6 & 15.0 & 7.6 & 6.8 \\
\hline Scale reliability (Cronbach's alpha) & .61 & .76 & .60 & .77 \\
\hline
\end{tabular}


Figure 5 shows the mean safety climate scores for the first, second and third quarters of 2006. The scores are all above the mid point of 4.0, indicating a generally positive safety climate on the project in both quarters. Scores for safety communication were consistently high (mean = 6.3) in all three measurement periods. Scores for supervisory safety leadership were initially very high in the first quarter of 2006 (mean=6.2). However, the mean supervisory safety leadership score fell to 5.2 in the second quarter, indicating a significant deterioration in workers' perceptions of supervisory safety behaviours during this period. Qualitative data, collected at the end of the safety climate survey converges with this result. Thematic analysis of these comments revealed supervisory issues as being of concern. For example, comments made included:

- Foremen better trained, attitude sometimes too relaxed toward OHS;

- By giving foremen more training in OHS so they are aware of any unsafe tasks workers might be doing...Some foremen only see the job ahead and not the safety around them;

- If our supervisor showed more compassion towards safety; and

- We need more supervision on the job, the foreman is never there.

In the third quarter perceptions of supervisory safety leadership had risen, once again to almost their first quarter levels (mean=6.1). Figure 5 also indicates a steady deterioration in perceptions of safety as a management priority, which fell from a mean score of 5.6 in the first quarter to 5.0 in the third quarter. Reasons for this are unclear. Perceptions of co-worker safety stewardship were consistently high throughout the measurement period.

Figure 5: Safety climate scores for first, second and third quarters 2006

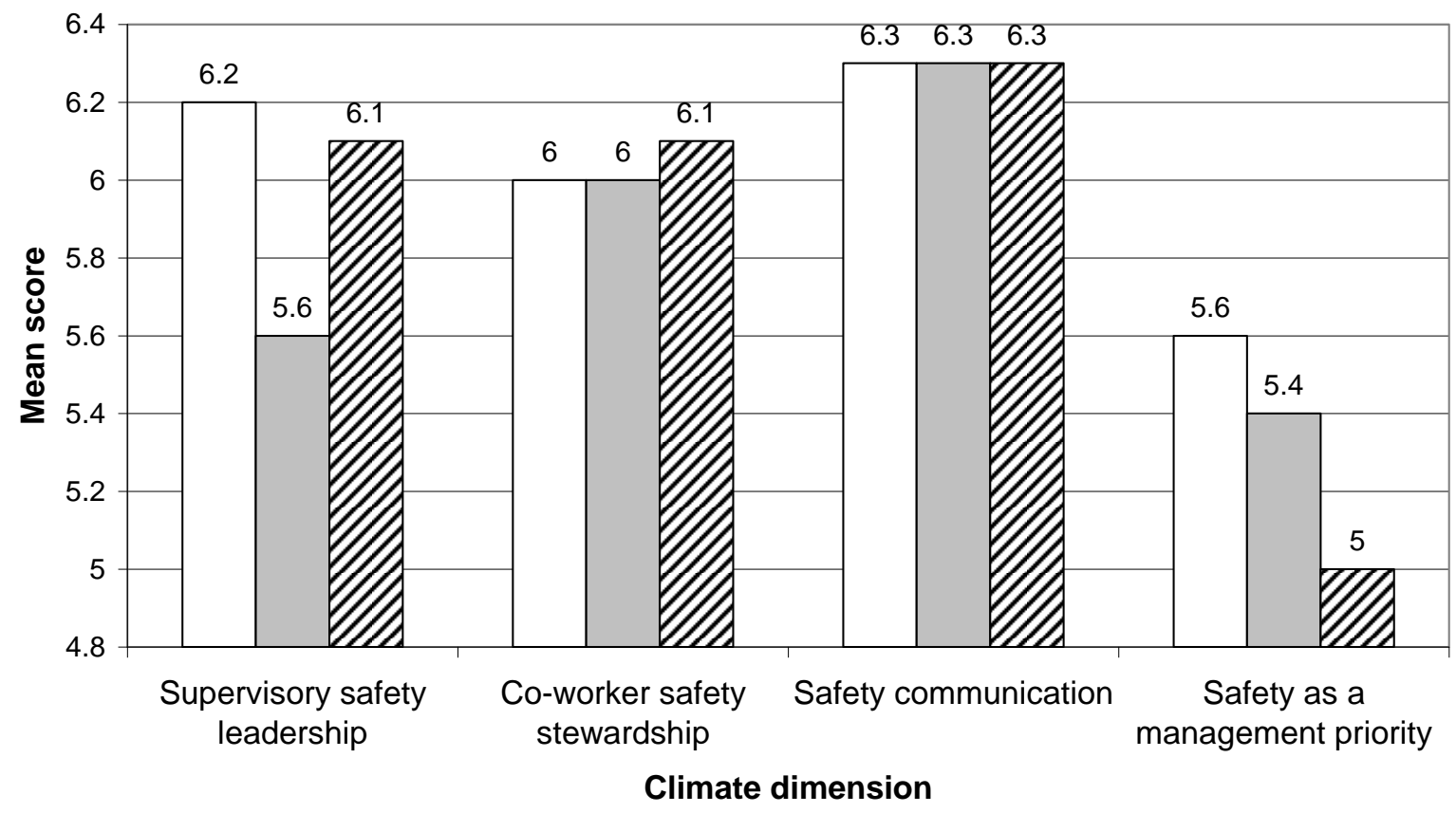

$\square$ Q1 $\square$ Q2 $\square$ Q3 


\section{Discussion}

\section{Usefulness of the measurement}

The usefulness of using multiple measures of OHS performance, including leading indicators and perception surveys is evident in the fact that, in the second quarter of 2006, a subtle deterioration in OHS performance is suggested by the results of the measurement. This change would have been undetected if reportable lost time injuries had been the only measure of OHS performance in place. Given its size and complexity, the case study project has demonstrated excellent OHS performance in terms of the absence of lost time injuries. Somewhat paradoxically, the absence of lost time injuries further reduces the usefulness of LTIFR in this project. The use of the safety index and the quarterly safety climate survey allows a finer grained analysis of trends in OHS performance that is sufficiently sensitive to detect subtle changes. Most importantly, this measurement enabled the early detection of emerging OHS issues before serious injuries occurred, equipping management with the information needed to implement targeted corrective strategies.

\section{Practical outcomes}

Both the safety index and the safety climate survey were used to diagnose specific OHS issues during the course of the project. This diagnosis resulted in the development of targeted OHS improvement interventions. For example, the safety index scores indicated an increase in injuries requiring first aid treatment in July 2006. Careful analysis of these injuries revealed that they were predominantly injuries to workers' hands. As a result of this analysis, a campaign to raise workers' awareness of the importance of wearing protective gloves was implemented in August 2006. As the project manager commented 'If we were just measuring LTIs or MTIs [medical treatment injuries] you would never know that.' The project manager also commented that the safety index focused attention on the importance of performing regular 'safety walks' on site, identifying and correcting OHS issues observed. In the opinion of the project manager, the frequency and effectiveness of safety walks was driven by the fact that these activities were measured and performance was reported back via the monthly safety index scores for the project. The project manager commented that sub-contractors were also more likely to engage with the principal contractors' OHS processes because the requirement to report their OHS performance using the safety index had been put into sub-contract documents. The project manager described the most important benefit of using the safety index as follows: '[it] is a really simple, easy way to articulate OHS performance to everyone in the project...more than we have got zero lost time injuries...If its less than the month before, it starts the questions.'

The quarterly measurement of safety climate also led to the development of interventions designed to improve OHS and worker well-being in the project. For example, following the second quarter application of the survey, in which supervisory safety leadership and perceptions of safety as a management priority were found to have deteriorated, the project management team delivered a short training session to all workers and supervisors on the project. This training was intended to refresh the original induction training provided to all personnel and communicate very clearly the importance of OHS on the project. The training was delivered by the project manager and the project safety manager, demonstrating the high level of management commitment to OHS. The safety climate measure was also perceived, by the project manager, to be very helpful in the management of OHS. He commented 'the biggest thing is that we listen and people feel and are heard because we respond to all of the comments that are made...people are heard in relation to how they feel about the project and their wellbeing.' 
Thus, from a practical point of view, both the safety index and safety climate survey were used to develop practical solutions to issues that would not have been apparent had OHS measurement relied solely on the use of traditional outcome measures.

\section{Validity}

Measurement is only useful to the extent that it is valid. This requires that a measure can be demonstrated to accurately and reliably measure what it claims to. A preliminary assessment of the validity of the two OHS measures developed for use in the case study project is discussed below. Some recommendations are made for further research and testing of the measurement methods.

Convergent validity refers to the extent that measures produce results that are consistent with those produced by other (preferably widely accepted) measures of the same concept. One form of testing convergent validity is to measure a concept using different methods.

Convergent validity is evident if the results are consistent across methods. The data collected from the case study project suggest an acceptable degree of convergent validity in that the climate survey data and the safety index scores are highly consistent with one another. The generally high safety climate scores are consistent with the high safety index scores throughout the entire measurement period. However, the second quarter climate scores (for the dimensions of supervisory safety leadership and OHS as a management priority) were considerably lower than those in the first quarter of 2006. This is consistent with the increase in near miss incidents occurring in June/July of 2006 and the steady increase in observed problems during safety walks. The consistency between the safety climate scores (a subjective measure of workers' safety perceptions) and the index scores (an objective measure of OHS outcomes and management processes) suggests convergent validity in these two measures. However, it must be noted that no attempt has been made to assess the extent to which this convergent validity arises because of a causal relationship between objective performance and subjective perceptions. For example, it is feasible that the change in workers' perceptions of supervisory safety leadership and OHS as a management priority were in fact caused by the increase in near misses and observation of safety problems during safety walks in the second quarter of 2006. Conversely, the increase in near miss incidents and observation of problems during safety walks could have been caused by behaviour change arising as a result of workers' perceptions that managers and supervisors were less concerned with OHS in the second quarter of 2006. Future research needs to be conducted to determine whether the two measures are causally related and, if a causal relationship is found, the direction and strength of this relationship.

Internal consistency is a type of convergent validity which seeks to demonstrate that there is a correlation between the different indicators of a concept. One test of internal consistency is seeking to demonstrate that indicators (e.g. questions in a survey) load unambiguously on their own factor in a Principal Components Analysis (PCA). A PCA of the safety climate survey data (see Table 2 ) revealed that item loadings were generally clear and unambiguous, with the exception of one item which double-loaded. All item loadings were greater than 0.5 further demonstrating the strong and robust factorial structure of the data. This suggests that the four safety climate dimensions were measured with acceptable internal consistency. Cronbach's alpha is a commonly used statistic to evaluate internal consistency. A Cronbach's alpha coefficient of 0.60 is generally considered to be acceptable for exploratory purposes, 0.70 is considered adequate for confirmatory purposes and 0.80 is considered good for confirmatory purposes. The Cronbach's alpha coefficients for the safety climate dimensions were all within the range of what is acceptable or better. These results indicate that the safety climate measure developed for the case study project possesses acceptable internal consistency. The internal consistency of the safety climate survey is also indicated by the fact 
that qualitative comments provided at the end of the survey were consistent with the quantitative climate dimension scores, for example comments relating to supervisory safety practices.

Discriminant validity refers to the principle that indicators for different concepts should not be so highly correlated that 'conceptual overlap' is a problem. Where indicators intended to measure one concept are highly correlated with indicators intended to measure another concept, discriminant validity is low and it is concluded that the indicators do not discriminate between the two concepts, i.e. they measure the same thing. The PCA techniques used to analyse the safety climate scores can help to ascertain the discriminant validity of the climate sub-scales. The results of the PCA revealed that all but one of the survey questions, loaded very clearly on only one of the four factors. The clarity of the four factor solution suggests that the four safety climate dimensions are conceptually different, indicating good discriminant validity.

Criterion or concurrent validity refers to the extent to which a measure correlates with a known and accepted standard measure of a particular criterion. In this case, the best known and standard measure of OHS performance would be the lost time injury frequency rate. Owing to the extremely good performance of the case study project in terms of the absence of any lost time injuries during the measurement period, it is impossible to ascertain whether the safety climate measure or the safety index correlated with this objective and accepted indicator of OHS performance. It is essential that future research examine the criterion validity of both safety measures to determine the extent to which they correlate with LTIFR and other objective indicators of OHS performance. This is best achieved by utilising the measures on a large number of construction projects with varying LTIFRs.

Content or face validity refers to the extent to which an instrument measures what it claims to measure and measures it in its entirety. Through combining the use of leading and lagging indicators of OHS performance with measures of workers' OHS perceptions in the climate survey, it is likely that the hierarchical model presented in Figure 1, provides a more comprehensive measure of OHS performance than single indicator measures, such as the traditional LTIFRs. However, the face validity of a number of the leading indicators used is uncertain and needs further investigation. Inaccurate interpretation of indicators is a threat to face validity in measurement. One unresolved issue in the case study measurement is the correct interpretation of the observed increase in near miss incidents in June/July 2006 and the increase in problems observed during safety walks during much of 2006. The interpretation of these trends developed within this paper is that they reflect a deterioration in OHS performance in the case study project. This interpretation is consistent with the differences in the first and second quarter safety climate scores. However, an alternative interpretation exists, i.e. the increase in near miss incidents and increasing observation of problems during safety walks reflect an improvement in the project's reporting culture. This alternative explanation is plausible and cannot be ruled out. Thus, the face validity of some of the indicators in the safety index must be carefully examined in future applications.

\section{Conclusions}

The measurement of OHS comprising lagging and leading performance indicators and a quarterly safety climate survey was perceived by the project's management team as being of great value. The measurement resulted in the implementation of a number of focused OHS improvement strategies that, in the opinion of the project manager, would not have been possible had the measurement relied exclusively on traditional lagging OHS performance indicators, such as LTIFRs. Preliminary data suggest the validity of the OHS management measures is good. The climate survey shows a strong and clear four factor structure with each 
of the climate components demonstrating acceptable internal consistency. The data collected using the two measurement tools was consistent, suggesting good convergent validity. However, the absence of lost time injuries in the case study project prevented the analysis of criterion validity and further testing of the measures on a larger sample of construction projects with varying levels of OHS performance is recommended.

\section{Limitations}

The measures were tested on a single case study project. Although longitudinal data are available for this project, there is a need to gauge the validity of the measures more broadly within the construction industry, thereby evaluating the external validity of the measures. External validity relates to the possible bias in the process of generalising conclusions from a sample to a population, to other populations, other settings and/or other time periods. Further development and testing on a company-wide basis is taking place.

\section{Acknowledgements}

Grateful thanks are extended to Greg Rotheram, Lara Tori and Andrew Stevenson who assisted with the development of the safety measurement methods and the collection and analysis of data presented in this paper.

\section{References}

Arezes, P. M. \& Miguel, A. S., (2003), The role of safety culture in safety performance measurement, Measuring Business Excellence, 7, 20-28.

Barling, J., Loughlin, C. E. \& Kelloway, E. K., (2000), Transformational leadership and occupational injuries: Development and test of a model linking transformational leadership and occupational injuries, Journal of Applied Psychology, 488-495.

Carder, B. \& Ragan, P. W., (2003), A survey-based system for safety measurement and improvement, Journal of Safety Research, 34, 157-165.

Cole, T., (2003), Final Report of the Royal Commission into the Building and Construction Industry, v6 Reform - Occupational Health and Safety, Commonwealth of Australia, Canberra.

Coyle, I., Sleeman, S. \& Adams, D., (1995), Safety climate, Journal of Safety Research, 22, 247-254.

Daniels, C. \& Marlow, P., (2005) Literature review on the reporting of workplace injury trends, HSL/2005/36, Health and Safety Laboratory, HSE, London.

Department of Employment and Workplace Relations/Office of the Australian Safety and Compensation Council, (2005), Guidance on the use of positive performance indicators to improve workplace health and safety, Commonwealth of Australia, Canberra.

Flynn, R., Mearns, K., O’Connor, P., \& Bryden, R., (2000), Measuring safety climate: identifying the common features, Safetv Science, 34, 177-194.

French, G., (2004), Health, safety and environment climate analysis: measuring performance in the Australian context, Journal of Occupational Health and Safety Australia \& New Zealand, 20, 155-167.

Glendon, A. I. \& Litherland, D. K., (2001), Safety climate factors, group differences and safety behaviour in road construction, Safety Science, 39, 157-188.

Health and Safety Executive, (2001), A guide to measuring health and safety performance, HMSO, London.

Hofmann, D. A., \& Morgeson, F. P., (1999), Safety-related behaviour as a social exchange: the role of perceived organisational support and leader-member exchange, Journal of Applied Psychology, 84, 286-296.

Hofmann, D. A. \& Stetzer, A., (1996), A cross-level investigation of factors influencing unsafe behaviours and accidents, Personnel Psychology, 49, 307-339.

McWilliams, G., Rechnitzer, G., Deveson, N., Fox, B., Clayton, A., Larsson, T. \& Cruickshank, I., (2001), Reducing serious injury risk in the construction industry, Policy Research Report No 9., Monash University Accident Research Centre, Melbourne.

Mearns, K., Whitaker, S. M. \& Flin, R., (2003), Safety climate, safety management practice and safety performance in offshore environments, Safety Science, 41, 641-680.

National Occupational Health and Safety Commission, (1994), Positive performance indicators for OHS: Beyond lost time injuries, Part 1 Issues, Commonwealth of Australia, Canberra.

National Occupational Health and Safety Commission, (1999), OHS performance measurement in the construction industry, Commonwealth of Australia, Canberra.

Neuman, W. L., (1994), Social Research Methods, $2^{\text {nd }}$ edition, Allyn and Bacon, Boston.

O'Brien, P., D. P., (1998), Business metrics for safety: A quantitative measurement approach to safety performance, Professional Safety, 43, 41-44. 
Parker, S. K., Axtell, C. M. \& Turner, N., (2001), Designing a safer workplace: Importance of job autonomy, communication quality and supportive supervisors, Journal of Occupational Health Psychology, 6, 211-228.

Patton, M. Q., (1990), Qualitative evaluation and research methods, $2^{\text {nd }}$ edition, Sage Publications, Newbury Park, CA.

Petersen, D., (1998), What measures should we use and why? Professional Safety, 43, 37-40

Petersen, D., (2005), Setting goals measuring performance, Professional Safety, , 43-48

Shannon, H. S., Robson, L. S. and Sale, J. E. M., (2001), Creating safer and healthier workplaces: role of organizational factors and job characteristics, American Journal of Industrial Medicine, 40, 319-334.

Simard, M. \& Marchand, A., (1994), The behaviour of first-line supervisors in accident prevention and effectiveness on occupational safety, Safety Science, 17, 169-185.

Simard, M. \& Marchand, A., (1995), A multi-level analysis of organizational factors related to the taking of safety initiatives by work groups, Safety Science, 21, 113-129.

Simard, M. \& Marchand, A., (1997), Workgroups' propensity to comply with safety rules: the influence of micro-macro organizational factors, Ergonomics, 40, 172-188.

Siu, O., Phillips, D. R. \& Leung, T., (2004), Safety climate and safety performance among construction workers in Hong Kong: The role of psychological strains as mediators, Accident Analysis and Prevention, 36, 359366.

Standards Australia, (2001), Australian/New Zealand Standard: Occupational health and safety management systems - General guidelines on principles, systems and supporting techniques, $2^{\text {nd }}$ edition, Sydney NSW.

Standards Australia, (1990), AS 1885.1-1990: Workplace injury and disease recording standard, Sydney, NSW.

Stricoff, R. S., (2000), Safety performance measurement: Identifying prospective indicators with high validity, Professional Safety, 45, 36-39.

Tinmannsvik, R. K. \& Hovden, J., (2003), Safety diagnosis criteria - development and testing, Safety Science, 41, 575-590.

Varonen, U. \& Mattila, M., (2000), The safety climate and its relationship to safety practices, safety of the work environment and occupational accidents in eight wood-processing companies, Accident Analysis and Prevention, 32, 761-769.

Vredenburgh, A. G., (2002), Organizational safety: Which management practices are most effective in reducing employee injury rates, Journal of Safety Research, 33, 259-276

WorkCover New South Wales, (2001), Safety meter positive performance measurement tool, WorkCover NSW, Sydney.

Zohar, D., (2000), A group-level model of safety climate: testing the effect of group climate on micro-accidents in manufacturing jobs, Journal of Applied Psychology, 85, 587-596.

Zohar, D., (2002), The effect of leadership dimensions, safety climate and assigned priorities on minor injuries in work groups, Journal of Organizational Behavior, 23, 75-92. 